\title{
Agent Based Simulation Research on Battery Recycling Logistics System
}

\author{
Lingzhu Yang ${ }^{\mathrm{a}}$, Yukun Liu ${ }^{\mathrm{b}}$ and Xueka Bian ${ }^{\mathrm{c}}$
}

School of automation, Beijing University of Posts and Telecommunications, Beijing 100876, China.

ayanglzbupt@163.com, blykbupt@163.com, cbxk_bupt@163.com

\begin{abstract}
This paper discusses and designs the structure and operation mode of the battery recycling logistics network with recycling unit, recycling point, collection center and recycling factory as the key logistics nodes. Considering the complicated interaction between the entities, the Agentbased model architecture is established. Finally, conduct a simulation experiment taking city $B$ as an example. It was found that a few policy adjustments of government and organizations could continuously improve system performance, and more quickly in certain circumstances. What's more, in specific situations, the behavior of surrounding recycling units may hinder the system.
\end{abstract}

Keywords: Battery recycling logistics system; Agent based simulation; Simio.

\section{Introduction}

Environmental pollution and energy shortages have always been a common threat and challenge for humanity. As electronic products are updated at an alarming rate, batteries meet a need for energy and at the same time, a large number of used batteries are generated which put tremendous pressure on the environment, ecosystems and human health. Discarding a button battery into nature will pollute 600,000 liters of water [1]. If the used batteries are not properly disposed, they will cause environmental pollution and huge waste of resources. Therefore, it is imperative to establish a sound battery recycling logistics system.

\section{The Design of Battery Recycling Logistics Network}

\subsection{Research Status and Related Laws and Regulations}

Foreign studies in battery recycling have been relatively mature. G. Kannan etc. established a network model multi-echelon, multi-period, multi-product closed-loop supply chain for used battery disposal and the lead recycling [2] Jovita Mercedes Hojas Baenas etc. have established an environmentally friendly reverse logistics framework for many small car battery manufacturers in the Midwest of São Paulo, Brazil [3].

There are also many theoretical achievements in China. Cao Juan proposed an evaluation model of used dry battery reverse logistics mode based on life cycle assessment method [4]. Liu Jing etc. used Agent theory and multi-agent theory to establish a recycling mode for used batteries of electric vehicles, and quantitatively resulted the degree of improvement of the battery used by the CCDD model through simulation experiments [5]. However, domestic processing technology is still lagging behind some other countries in the world. There are few results in the field of research on the combination of household used battery recycling system and ABM(Agent-based modeling) method.

In addition, Chinese related laws and regulations of battery recycling are not perfect, and there is no clear provision for battery classification. By sorting out the existing laws and regulations, the paper find the disputed policies: "The recycling of used primary batteries shall be carried out cautiously by the recycling responsible unit. At present, in the absence of technical and economic conditions for effective recycling, centralized collection of used primary batteries that have met national low or no mercury requirements is discouraged." This paper believes that it cannot be simply interpreted as the current social media public opinion that "used batteries do not need to be recycled, and can be discarded with household garbage". Taking into account the views of different parties, it is concluded that it is necessary to establish a used battery recycling system. 
This paper discuss and propose a suitable battery recycling logistics network structure based on the foreign battery recycling network structure,the domestic low-value pollution waste recycling network structure research, and the solid waste recycling network structure with no seasonal fluctuation.

\subsection{Analysis and Design of Used Battery Recycling Logistics Network Structure}

Through the analysis of the status at home and abroad, this paper will consider multiple factors such as the research purpose, the data collection and the domestic status, and then simplify the discussion of some logistics nodes, such as the battery factory (Small degree of influence), the professional transportation company (Complex transportation mode). The simplified logistics network contains recycling units, collection points, collection centers, recycling factories, and social volunteer organizations, shown in Fig. 1.

The recycling unit will deliver the battery to the collection point or discard it at will. They may be individuals, families, communities, urban areas, etc. The battery is stored at the recycling point and waiting for transportation. The recycling point may be a battery recycling bin, a recycling site, a battery retailer, a nonprofit organization office, a neighborhood office, and the like. The collection center mainly undertakes the collection, classification and short-term storage of used batteries transported from the collection points. The establishment of the collection center needs to consider economic benefits and land resources. The recycling factory at the end of the logistics network is responsible for recycling the used batteries transported here and get useful materials as a result. The voluntary organization collects the batteries at the door for free and transports them to the appropriate disposal location.

According to the research conclusions of low-value waste [6]and the operation experience of domestic garbage recycling system, the used battery reycling logistics system is established in this paper,which is managed by the government and work at a fixed time and route based on recycling amount and domestic requirements of garbage transportation vehicles. Due to the fixed recycling work, the paper does not involve dynamic planning transportation route and predicting recycling time. If residents need, volunteers of the organization will be on-site for used batteries. The voluntary organization will mainly ease the supply of transportation that can not be solved by the regular route at the collection point. Since the transportation service can be regarded as immaterial product, the regular transportation is the push flow, while the home recycling of the volunteers is the pull flow. In this paper, the whole system is a push-pull logistics system.

The behaviors of government and organizations will affect the reaction of each node on the logistics network. Therefore, the government and organizations related is included. So far, the used battery recycling logistics system designed in this paper is shown in Fig. 1.

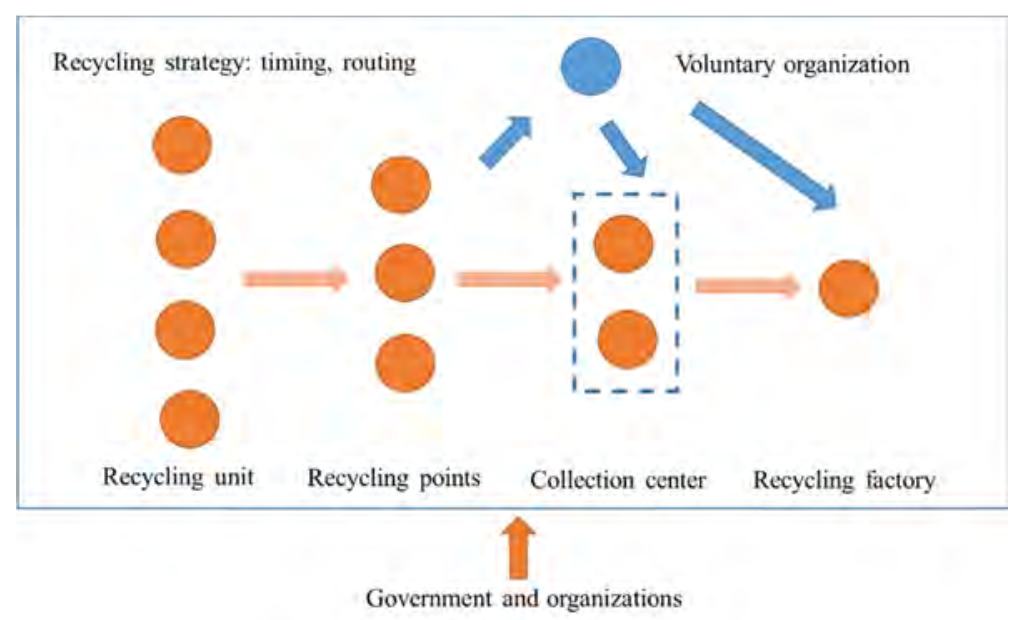

Fig. 1 Battery recycling logistics network structure 


\section{Agent-based Simulation Model}

\subsection{The Construction of Agent-based Model}

\subsubsection{The Determination of Agent}

By the literature review, it was found that the ABM method has not been applied in the field of battery recycling. Some low-value polluting waste recycling systems or supply chains are studied. In this way, some universal agents are defined, like recycling unit Agent, recycling factory Agent, transportation company Agent.

Government policies support the operation of recycling factory and the government carries out transportation work. So transport company Agent and recycling factory Agent are not considered. The government Agent, voluntary organization Agent and market Agent are in the model.

\subsubsection{Interaction Mechanism Between Agents}

The recycling unit Agent decision function is built. The research on waste recycling behavior at home and abroad is mainly based on behavioral decision theory. Ajzen's rational behavior theory (subjective norms, behavioral attitudes, and perceived behavioral control determine the behavioral intentions together) is currently one of the most widely used theories in the field of behavioral research.

The Agent behavior of the battery recycling logistics system in the papaer is based on the empirical research results of Zhengzhou residents participating in the electronic waste recycling behavior conducted by Xiaomeng Si [7].

Since environmental knowledge, subjective norms, recycling habits and other factors lead to many Agent categories, no distinction is made due to the software version.

As the dependent variables of the government and the organization Agent behavior, Laws and regulations, and environmental education will affect the behavior of the recycling unit. By the research on low-value waste recycling, the surrounding recycling units' behaviors are involved in recycling unit Agent decision-making. A questionnaire survey on laws and regulations, environmental education, and surrounding recycling units' behaviors was done. Collected valid data, an analysis of different factors influence on recycling unit Agent behavior is completed.

The linear function form is assumed for the recycling unit decision function:

$$
P_{\text {unit }}=a x_{1}+b x_{2}+c x_{3}
$$

$P_{\text {unit }}$ : The probability that the recycling unit appears recycling behavior;

$x_{1}$ : The degree of perfection of laws and regulations;

$x_{2}$ : Environmental education promotion level;

$x_{3}$ : Behaviors of surrounding recycling unit Agents;

$a$ : The weight coefficient of legal and regulatory factor;

$b$ : The weight coefficient of environmental education factor;

$c$ : The weight coefficient of surrounding recycling unit Agents behaviors factor.

Considering study time and difficulty level, the simpler and clearer Analytic Hierarchy Process (AHP) is used to determine the weight coefficients value. First, the importance comparison between the various indicators is carried out. The importance scale uses the international general scale table, as shown in Table 1.

This paper does a questionnaire survey to measure the importance of the indicators. The results of the assessment are shown in Table 2 below. ( $a$ : legal and regulatory factors; $b$ : environmental education factors; $c$ : surrounding recycling unit Agents behaviors factors.) 
Table 1. AHP scale table

\begin{tabular}{cc}
\hline Scaling & Definition and Description \\
\hline 1 & Two factors have the same importance for attributes \\
3 & Comparison of two factors, one is slightly more important than the other \\
5 & Comparison of two factors, one is significantly more important than the other \\
7 & Two factors are compared, one is much more important than the other \\
9 & Two factors are compared, one is extremely more important than the other \\
$2,4,6,8$ & Indicates that there is a need to compromise between the two standards \\
$1 / \mathrm{bij}$ & Counter comparison between two factors \\
\hline
\end{tabular}

Table 2. Judgment matrix result of the survey

\begin{tabular}{cccc}
\hline & $\mathrm{a}$ & $\mathrm{b}$ & $\mathrm{c}$ \\
\hline $\mathrm{a}$ & 1 & $5 / 22$ & $50 / 237$ \\
$\mathrm{~b}$ & $22 / 5$ & 1 & $25 / 63$ \\
$\mathrm{c}$ & $237 / 50$ & $63 / 25$ & 1 \\
\hline
\end{tabular}

Then, the paper normalize the judgment matrix above, and the results are shown in Table 3.

Table 3. The result of judgment matrix normalization

\begin{tabular}{ccccc}
\hline & $\mathrm{a}$ & $\mathrm{b}$ & $\mathrm{c}$ & Sum of Lines \\
\hline $\mathrm{a}$ & 0.10 & 0.06 & 0.13 & 0.29 \\
$\mathrm{~b}$ & 0.43 & 0.27 & 0.25 & 0.95 \\
$\mathrm{c}$ & 0.47 & 0.67 & 0.62 & 1.76 \\
\hline
\end{tabular}

Normalize the vector $w=(0.29,0.95,1.76)^{T}$, and get the eigenvector $W=(0.10,0.32,0.58)^{T}$. The calculation result of maximum eigenvalue $\lambda \max$ of judgment matrix is as follows.

$$
\begin{gathered}
B w=\left(\begin{array}{ccc}
1 & \frac{2}{55} & \frac{50}{237} \\
\frac{22}{5} & 1 & \frac{25}{63} \\
\frac{237}{50} & \frac{63}{25} & 1
\end{array}\right)\left(\begin{array}{l}
0.10 \\
0.32 \\
0.58
\end{array}\right)=\left(\begin{array}{l}
0.30 \\
0.99 \\
1.87
\end{array}\right) \\
\lambda_{\max }=3.09
\end{gathered}
$$

The consistency test is performed on the above results, and the matrix consistency index CI is calculated as follows.

$$
C I=\frac{\lambda_{\max }-\mathrm{n}}{\mathrm{n}-1}=0.05
$$

Table 4. The standard value of average random consistency index RI

\begin{tabular}{cccccc}
\hline $\mathrm{n}$ & 1 & 2 & 3 & 4 & 5 \\
\hline $\mathrm{RI}$ & 0 & 0 & 0.58 & 0.9 & 1.12 \\
$\mathrm{n}$ & 6 & 7 & 8 & 9 & 10 \\
$\mathrm{RI}$ & 1.24 & 1.32 & 1.41 & 1.45 & 1.49 \\
\hline
\end{tabular}

Random consistency ratio is $C R=\frac{\mathrm{CI}}{\mathrm{RI}}=0.09<0.1$, and hierarchical total ordering passes consistency test. So, the values of $a, b$, and $c$ are $0.10,0.32$, and 0.58 .

The government and organizations decision function is built. The behavior of the government and organizations is mainly to improve laws and regulations and carry out environmental education. The decision is affected by the current market recycling situation. This paper takes the recycling rate as 
influence factor of government and organizations behavior. The government and organizations Agent decision function is as follows.

$$
P_{\text {government }}=\left\{\begin{array}{l}
1, r \leq r_{0} \\
0, r>r_{0}
\end{array}\right.
$$

$P_{\text {government }}$ : The probability of government and organizations to improve laws and regulations and carry out environmental education;

$r$ : The market current recycling rate;

$r_{0}$ : The target value of market recycling rate, also means the threshold for behavioral stop.

The market Agent decision function is built. The market agent mainly sends the relevant message of the overall battery recycling rate $r$ of the system to the government and the organizations agent. In reality it is the data statistics department. The behavior improvement messages occur when the current recycling rate $r$ is less than the target market recycling rate $r_{0}$ after a period of time of the last government decision. Its decision function is as follows.

$$
P_{\text {market }}=\left\{\begin{array}{c}
1, \frac{N_{\text {recycled }}}{N_{\text {recycled }}+N_{\text {notrecycled }}}<r_{0} \text { and } T_{n}-T_{n-1} \geq T_{0} \\
0, \frac{N_{\text {recycled }}}{N_{\text {recycled }}+N_{\text {notrecycled }}} \geq r_{0}
\end{array}\right.
$$

$P_{\text {market }}$ : The probability that the market report to the government that the market has a low rate of recycling currently;

$N_{\text {recycled }}$ : The number of used batteries entering the recycling logistics system;

$N_{\text {notrecycled }}$ The number of used batteries do not entering recycling logistics system, which may be discarded;

$r_{0}$ : The target market recycling rate, also means the threshold for behavioral stop;

$T_{n}$ : The time of the Government's $n^{\text {th }}$ decision;

$T_{0}$ : The time period of market statistics.

In summary, the interaction mechanism between Agents is shown in Fig. 2. The recycling unit Agent is affected by environmental education and the degree of perfection of laws and regulations, which are determined by the relevant work of the government agent, such as strengthening environmental education and improving regulations. On the other hand, the recycling unit Agent is also affected by the surrounding recycling unit Agents. When the behavior of the surrounding recycling unit Agents tends to recycle, the probability that the recycling unit appears recycling behavior will increase. Whether the government agent does the above work is mainly determined by the messages about the system recycling rate from the market agent.

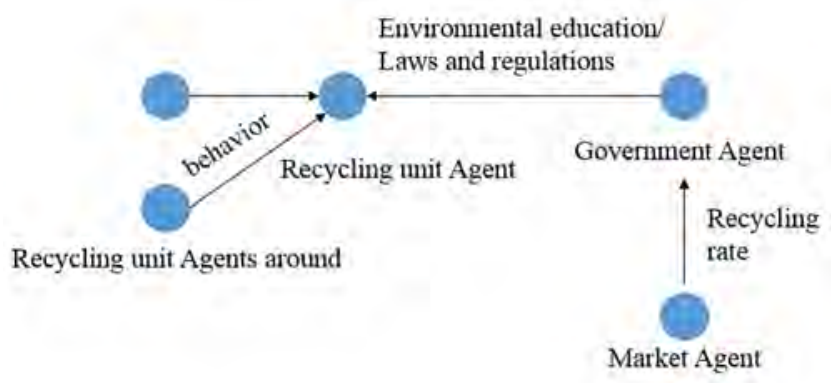

Fig. 2 Interaction mechanism betweem Agents

\subsection{The Construction of Simulation Model}

The battery recycling logistics model is built and implemented with Simio Academic Version. Compared with visual effects, the logic model is more important. In the process of establishing the 
model in this chapter, the paper focus on the logic fidelity of the simulation model. Fig. 3 shows the simulation model simplified interface of a battery recycling supply chain, which is the basic core part of the overall model.

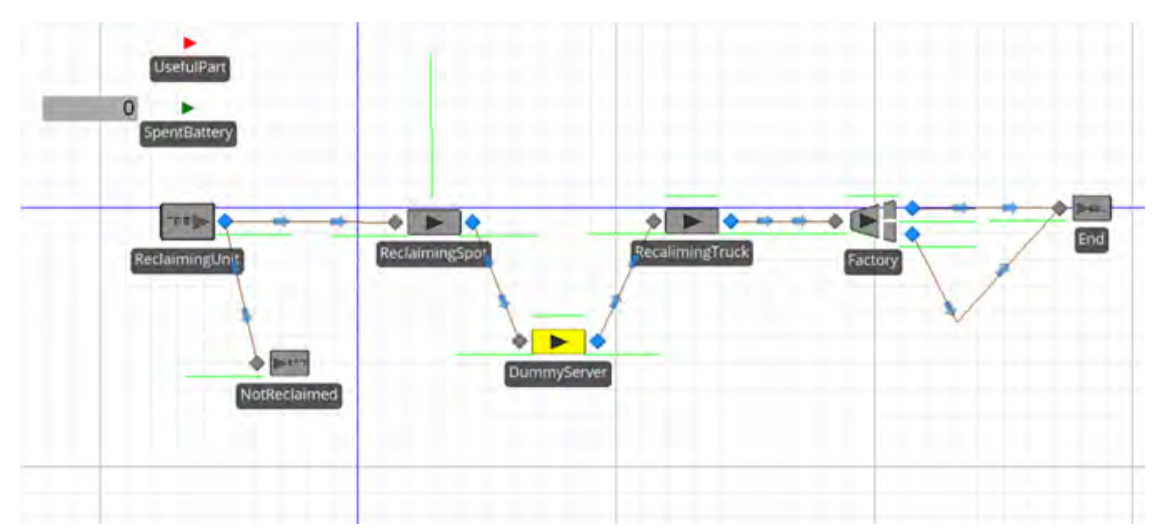

Fig. 3 Battery recycling logistics core model interface

The key symbols and meanings of the model are shown in Table 5.

Table 5. The key symbols and meanings of the model

\begin{tabular}{cc}
\hline The Key Symbols & Meaning \\
\hline SpentBattery & The entity object of used batterys \\
ReclaimingUnit & The object of battery recycling unit \\
ReclaimingSpot & $\begin{array}{c}\text { The object of battery recycling point } \\
\text { The object of transport vehicle } \\
\text { ReclaimingTruck } \\
\text { Factory }\end{array}$ \\
The object of recycling factory \\
EnvoronmentalAwareness & The state variable of recycling unit environmental awareness \\
LegalConsciousness & The state variable of recycling unit legal awareness \\
BehaviourRecord & The state variable of recycling unit behavior record \\
LawPerfection & The state variable of degree of legal perfection \\
PropagandaPower & The state variable of environmental protection work \\
SystemTargets & The state variable of target market recycling rate \\
RecycledNumber & The state variable of the number of recovered batteries \\
DecisionValue & The decision function value of recycling unit \\
InformRecycledRateTimer & Market recycling rate statistical behavior time generator \\
\hline
\end{tabular}

\section{Case Study}

\subsection{Parameter Settings}

Based on the background of city B, Donghua Xinxin Used Battery Recycling Center in the certain district of city B is the recycling factory, which was founded by volunteer Zixin Wang. According to the data research, city B's battery consumption is about 300 million, equivalent to 6,000 tons. While the current processing capacity of Donghua Xinxin Used Battery Recycling plant Center is 2,000 tons/year, it is theoretically necessary to get additional devices of 4,000 tons/year.

There is no reference data for the arrival of used batteries in city B currently. According to the data survey and life experience in city B, the battery is life necessities, and the demand shows no significant seasonal fluctuations. In this paper, the distribution of the number of batteries required is uniform in time, so the distribution of the arrival time interval of the used batteries is simplified to a constant distribution. 
Based on the city B's battery usage, the population of city B districts and the administrative division of the main streets, the distribution of used batteries in different districts of city B can be set as shown in Table 6. Transportation distance and time from the computing center of gravity of each part to Donghua Xinxin are set by Baidu map software.

The voluntary organization transport which cannot be solved by the conventional transportation vehicles everyday. Its processing capacity is 1-2 tons/day, influenced by the distance from the location of the transportation task to the recycling factory.

In the case, the intensity of regulation indicates that the intensity of each regulation will raise the legal awareness and environmental awareness of the recycling unit Agent. In order to discover the "emergence" effect that may be produced by the government, every low intensity regulation increases the relevant parameters by $10 \%$.

Table 6. The parameter setting of city B's administrative district used batteries

\begin{tabular}{ccccccccc}
\hline $\begin{array}{c}\text { Admini- } \\
\text { strative } \\
\text { District }\end{array}$ & Population & $\begin{array}{c}\text { Annual } \\
\text { used } \\
\text { batteries } \\
\text { (ton) }\end{array}$ & $\begin{array}{c}\text { Annu- } \\
\text { al used } \\
\text { after } \\
\text { merger } \\
\text { (ton) }\end{array}$ & $\begin{array}{c}\text { Time } \\
\text { interval } \\
\text { of } \\
\text { arrival } \\
\text { per ton } \\
\text { (day) }\end{array}$ & $\begin{array}{c}\text { Day } \\
\text { waste } \\
\text { (ton) }\end{array}$ & $\begin{array}{c}\text { Number } \\
\text { of } \\
\text { transport } \\
\text { vehicles }\end{array}$ & $\begin{array}{c}\text { One-time } \\
\text { Transportable } \\
\text { battery } \\
\text { capacity } \\
\text { (ton) }\end{array}$ & $\begin{array}{c}\text { Number } \\
\text { of } \\
\text { recycling } \\
\text { points }\end{array}$ \\
\hline 1 & 317000 & 96.9 & & & & & & \\
2 & 373000 & 114.1 & 354.1 & 1 & 1 & 1 & 1 & \\
3 & 468000 & 143.1 & & & & & & \\
4 & 1661000 & 507.9 & & & & & & \\
5 & 877000 & 268.2 & 903.3 & 0.4 & 2.5 & 3 & 3 & \\
6 & 416000 & 127.2 & & & & & & \\
7 & 290000 & 88.7 & 380.7 & 1 & 1 & 1 & 133 \\
8 & 955000 & 292 & & & & & & \\
9 & 3281000 & 1003.3 & 2087.2 & 0.2 & 5.7 & 6 & 6 & 760 \\
10 & 3545000 & 1084 & & & & & & \\
\hline
\end{tabular}

\subsection{Cost Analysis}

The main cost of recycling point includes recycling equipment. 1359 recycling bins need to be built in the case. Refer to the data of the battery recycling website, 55 recycling bins are maintained by the community now. Therefore, it is still necessary to build 1304 recycling bins in City B. One bin costs 1000 yuan and can be used for 3 years. The cost is:

$$
C_{\text {spots }}=430,000(\text { yuan } / \text { year })
$$

According to the data research, the cost of the factory expansion is about 10.4 million yuan. Additional equipment costs 690,000 yuan / year for depreciation. Factory operating costs 72,000 yuan / year, and the factory earns recycling income of 20,000 yuan / ton. The factory is responsible for the $62 \%$ of the recycling task in city B.

The cost of recycling factory is about:

$$
C_{\text {factory }}=762000 * 62 \%=472000(\text { yuan } / \text { year })
$$

The income of recycling factory is:

$$
P_{\text {factory }}=20000 * n(\text { yuan } / \text { year })
$$

$\mathrm{n}$ : Tons of batteries which recycling factory disposes per year. 
Transportation costs need to consider the salary of transport drivers and assistants. The salary of the two workers is about 7,339 yuan / month. The salary of eleven transport vehicles is about 80,929 yuan / month. 11 vehicles cost 48,400 yuan/year for depreciation. Therefore, the fixed transportation cost is about:

$$
C_{\text {transportf }}=48400+80729 * 12=1017000(\text { yuan } / \text { year })
$$

The variable transportation cost is about:

$$
C_{\text {transportv }}=10400 * m(\text { yuan } / \text { year })
$$

$m$ : The kilometers of the vehicles driving a year.

\subsection{Experimental Design}

The initial environmental recycling awareness and legal awareness of the recycling unit are uniformly distributed in the definition domain and in the geospatial space because of the software version. The initial recycling rate of the system is $2 \%$. Considering the uniformly distributed awareness level, the natural regulation effect will get a recycling rate of about $50 \%$ at end. This experiment takes a medium to high target recycling rate of $80 \%$. Initial legal perfection and environmental education efforts are $0 \%$ (no behavior).

Through a lot of observation, the system generally get the 50\% recycling rate after 424 days under natural conditions(no behavior).

Since the interval of decision-making behavior of the government and the organizations is about 241 days, each regulation behavior improve about $10 \%$ of the related parameters of the recycling units. By the same 424-day length of time, the result can show how the government and organizations' regulatory behavior adjust the system recycling rate. The parameter settings of decision variable in this experiment are shown in Table 7. Each scenario is repeated 10 times to get the experimental results.

Table 7. The parameter settings of decision variable in this experiment

\begin{tabular}{cc}
\hline Scenario & Government regulation \\
\hline 1 & No behavior \\
2 & Have (low intensity) regulation behavior \\
\hline
\end{tabular}

\subsection{Result Analysis}

In the scenario 1 , the recycling rate and system total profit at system termination are shown in Table 8.

The Recycling Rate



Fig. 4 System recycling rate change chart of scenario 1 
Table 8. Result analysis of scenario 1

\begin{tabular}{ccc}
\hline & Recycling rate & Total system profit \\
\hline Average & $49.97 \%$ & 6702231.5200 \\
Standard deviation & 0.0028 & 28110.1251 \\
$\mathrm{t}$ & 1.8331 & 1.8331 \\
Interval half length & 0.0016 & 16294.9112 \\
Left interval & 0.498 & 6685936.6087 \\
Right interval & 0.5013 & 6718526.4312 \\
Relative error & 0.0032 & 0.0024 \\
\hline
\end{tabular}

Because the recycling unit's willingness to recycle doesn't suit the initial recycling rate of the system, a natural regulation effect arise in the system. Under the automatic adjustment of the system, the system recycling rate increased from $2 \%$ to $49.97 \%$, as shown in Fig. 4 . After about 248 days, the economic investment accumulated in the previous period is equal to the economic return, that is, breakeven. At the end of the system (after 424 days), the total accumulated profit of the system is 6702231.52 yuan.

In the scenario 2, the recycling rate and system total profit results at system termination are shown in Table 9.

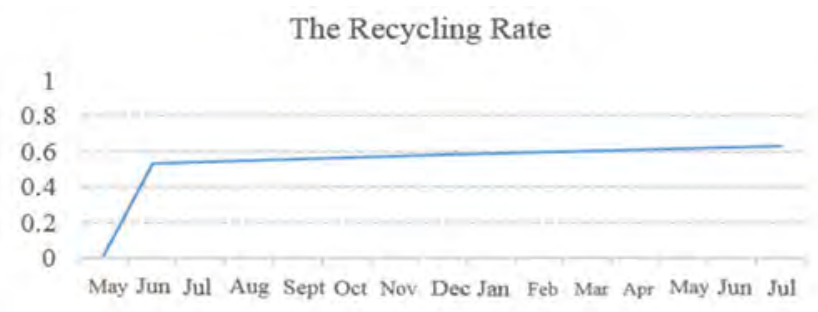

Fig. 5 System recycling rate change chart of scenario 2

Table 9. Result analysis of scenario 2

\begin{tabular}{ccc}
\hline & Recycling rate & Total system profit \\
\hline Average & $63.29 \%$ & 11286409.4000 \\
Standard deviation & 0.0126 & 25163.9107 \\
$\mathrm{t}$ & 1.8331 & 1.8331 \\
Interval half length & 0.0073 & 14587.0462 \\
Left interval & 0.6256 & 11271822.3538 \\
Right interval & 0.6402 & 11300996.4461 \\
Relative error & 0.0115 & 0.0013 \\
\hline
\end{tabular}

With the behavior of the government and organizations, the income of the recycling factory increased compared with the first scenario. With the total cost unchanged, the growth rate of the total profit of the system increased at the same level. After about 193 days, the system recovered the previous investment cost and at breakeven point. At the end of the operation, the total system profit is about 11286409.40 yuan.

A comparison of the results of two scenarios shows that the government and organizations are conducive to improving the system operational efficiency. In the case that the target recycling rate is not achieved, the government and organizations' low-level regulation can continuously improve the system recycling rate. Compared with the scenario 1 , the recycling rate is increased by $13.32 \%$, and the total profit increase obviously which is about 4.59 million. The system breakeven time is about 55 days earlier.

In the natural state (no behavior) with a low initial recycling rate of the system, even if the residents have medium or even high recycling willingness, the system automatic adjustment cannot be 
completed quickly. The reason is the recycling unit is greatly affected by the behavior of the surrounding recycling units, which is consistent with the questionnaire survey result that the value of $\mathrm{c}$ is the highest.

In the early stage of system operation, the low-level regulation of the government and organizations has a great effect on eliminating the mismatch between residents' willingness to recycle and system recycling efficiency.It can improve the system recycling rate to match the willingness to recycle $(50 \%)$ in a very short time. In the later stage of the system, the regulation effect reduced the growth rate of the system recycling rate, but the total profit of the system increase faster, about 26,000 yuan/day, which was mainly due to the continuous increase of the system recycling rate.

\section{Conclusion}

The battery logistics recycling system established in this paper is practical from the economic and technical point of view. Due to the low recycling rate and the low value of batteries recycled in reality, the government and organizations could provide financial support in the initial stage of system to maintain the normal operation of the recycling system. Then the system gradually achieves profitability. Governments and organizations should actively support and regulate the battery logistics recycling system including improving laws, which can speed up the elimination of the mismatch between residents' willingness to recycle and the current recycling rate of the system, improving the performance of the recycling system. Under certain conditions of the questionnaire survey result, enhancing environmental education will do better than perfecting laws and regulations. In the case that the residents' willingness to recycle matches the system recycling rate, the government and the organizations should actively regulate and control the system, raising the system recycling rate to the target level continuously.

\section{References}

[1]. Lijun Sheng. Analysis of problems and countermeasures about recycling used batteries. Journal of Green Science and Technology. Vol.04(2012) No.04, p. 216-217.

[2]. Kannan G, Sasikumar P, Devika K.A genetic algorithm approach for solving a closed loop supply chain model: A case of battery recycling. Applied Mathematical Modelling. Vol.34(2010) No.3. p. 655-670.

[3]. Jovita Mercedes Hojas Baenas, Rosani de Castro, Rosane Aparecida Gomes Battistelle et al. A study of reverse logistics flow management in vehicle battery industries in the mid-west of the state of Sao Paulo (Brazil).Journal of cleaner production. Vol.19(2011) No. 2.p. 168-172.

[4]. Juan Cao: Evaluation of Reverse Logistics Model of Used Dry Battery Based on Life Cycle Assessment Method. (Master Degree, Beijing JiaoTong University, China. 2009.)

[5]. Jing Liu, Guoqiang Cai, Haibo Liu. Study on Recycling Model of Electric Automobiles Based on Agent. Logistics Technology.Vol.12(2012) No.12. p.287-290.

[6]. Yanhua Guo. From cracking "garbage siege" to developing and utilizing "urban minerals"--Basic ideas and suggestions for recycling and utilization of low-value waste in Guangzhou. Ecological Economy.Vol.2(2013) No.2. p.417-419.

[7]. Xiaomeng Si: Empirical Study on Residents' Participation in E-waste Recycling Behavior. (Master Degree, Henan Normal University, China,2015.) 